\title{
IDENTIFIKASI POTENSI ALAM DESA DULANGEYA SEBAGAI KAWASAN WISATA MENGGUNAKAN SISTEM INFORMASI GEOGRAFIS

\author{
Identification of the Natural Potential of Dulangeya Village as a Tourism Area Using
} Geographic Information Systems
}

\author{
Herman Saleh ${ }^{1}$, Arthur Gani Koto ${ }^{2}$, Ivan Taslim ${ }^{3}$ \\ ${ }^{1}$ Sarjana Program studi Geografi Universitas Muhammadiyah Gorontalo, Indonesia \\ ${ }^{2,3}$ Program studi Geografi Universitas Muhammadiyah Gorontalo, Indonesia \\ Email korespondensi : hermansaleh78@gmail.com
}

DOI: http://dx.doi.org/10.31314/jsig.v1i2.173

\begin{abstract}
Dulangeya village has natural potential that can be used as tourism area. The objective of research was to identify the natural potential in Dulangeya village to become a tourism area by utilizing Geographic Information System applications. The data used are land cover, slope and geological maps. The method and data analysis used interviews and field observation methods, which are the methods that aim to determine the level of feasibility of natural potential in Dulangeya Village which analyzed spatially and scoring. Based on the results of the scoring analysis for each assessment criteria are attractiveness $(94.44 \%)$, accessibility $(70.83 \%)$, accommodation $(33.33 \%)$ and facilities and infrastructure (70\%). The results showed that Dulangeya Village is one of villages in Botumoito sub district which has potential of natural resources that are feasible to be used as one of the natural attractions.
\end{abstract}

Keywords: Nature Potential, Tourism, Dulangeya Village, GIS

\begin{abstract}
Abstrak - Desa Dulangeya memiliki potensi alam yang dapat dijadikan sebagai kawasan wisata. Tujuan penelitian ini adalah untuk mengidentifikasi potensi alam di Desa Dulangeya menjadi kawasan wisata dengan memanfaatkan aplikasi Sistem Informasi Geografis (SIG). Adapun data yang digunakan adalah peta tutupan lahan, lereng dan geologi. Metode dan analisis data yang digunakan adalah metode wawancara dan observasi lapangan yaitu metode yang bertujuan untuk mengetahui tingkat kelayakan potensi alam di Desa Dulangeya yang akan dijadikan sebagai kawasan wisata yang dianalisis secara spasial dan skoring. Berdasarkan hasil analisis skoring untuk setiap kriteria penilian adalah daya tarik $(94,44 \%)$, aksesibilitas $(70,83 \%)$, akomodasi $(33,33 \%)$, sarana dan prasana $(70 \%)$. Berdasarkan hasil analisis menunjukkan bahwa Desa Dulangeya merupakan salah satu Desa di Kecamatan Botumoito yang memiliki potensi SDA yang layak untuk dijadikan sebagai salah satu obyek wisata alam.
\end{abstract}

Kata Kunci: Potensi Alam, Wisata, Desa Dulangeya, SIG 


\section{PENDAHULUAN}

Di era globalisasi saat ini, sektor pariwisata merupakan industri terbesar dan terkuat dalam pembiayaan ekonomi global dan juga akan menjadi pendorong utama perekonomian dunia pada Abad ke dua puluh satu, serta menjadi salah satu industri yang mendunia. Untuk itulah sektor parawisata dilirik sebagai salah satu alternatif yang dapat dikembangkan untuk membantu pembangunan di suatu daerah (Soebagyo, 2012). Pengembangan obyek dan daya tarik wisata yang ada di permukaan bumi hanya dapat dipetakan melalui Sistem Informasi geogarafis (SIG). SIG merupakan sejenis perangkat lunak yang dapat digunakan untuk pemasukan, penyimpanan, manipulasi, menampilkan, dan keluaran informasi geografis mengenai objek yang di permukaan bumi berupa objek-objek yang potensial untuk dijadikan sebagai kawasan pariwisata, kawasan pemukiman, dan kawasan transmigrasi (Bafdal et al, 2011). Dengan demikian pengembangan obyek dan daya tarik wisata secara optimal mampu meningkatkan pertumbuhan ekonomi, yang dengan mempertimbangkan hal tersebut maka penanganan yang baik sangat diperlukan dalam upaya pengembangan obyek-obyek wisata di Indonesia. Berdasarkan hal tersebut, bahwa Desa Dulangeya yang letaknya di pesisir laut dengan keragaman potensi alam yang masih perlu diinventarisir, senantiasa membutuhkan penilaian dalam hal ademi lebih lanjut agar dapat dikembangkan menjadi salah satu obyek daya tarik wisata agar kiranya dapat menjadi salah satu penunjang perekonomian masyarakat di bidang pariwisata.

Desa Dulangeya merupakan salah satu desa yang berada di Kecamatan Botumoito. Berdasarkan data profil Desa Dulangeya tahun 2016 bahwa jumlah penduduk 665 jiwa yang memiliki presentase pendidikan tamat SD 85\%, tamat SMP 6\%, tamat SMA 8\% serta tamat pendidikan perguruan tinggi dengan jumlah $1 \%$. Berdasarkan uruain diatas bahwa tingkat pendidikan di Desa Dulangeya sangat memprihatinkan hal ini juga dibuktikan dengan presentase tingkat pekerjaan tertinggi dibidang pertanian $80 \%$ dan presentase terendah yaitu PNS 1\%, dengan demikian bahwa pemahaman masyarakat Desa Dulangeya terhadap kekayaan alam yang berpotensi untuk dijadikan sebagai obyek daya tarik wisata masih sangat minim. Adapun potensi alam yang menjadi obyek daya tarik wisata di Desa Dulangeya yaitu pantai berpasir putih, mangrove, batuan dan sumber mata air panas. Berdasarkan potensi tersebut maka penulis melakukan penelitian terkait dengan identifikasi potensi alam yang akan dijadikan sebagai salah satu obyek daya tarik wisata alam dengan memanfaatkan aplikasi SIG.

\section{METODE PENELITIAN}

Penelitian ini akan dilakukan di Desa Dulangeya [0.48846 $\left.{ }^{\circ} \mathrm{LU}, 122.24211^{\circ} \mathrm{BT}\right]$, Kecamatan Botumoito Kabupaten Boalemo. Adapun alasan pemilihan lokasi penelitian adalah karena dulangeya merupakan salah satu desa yang terletak di pesisir laut Teluk Tomini yang juga memiliki manifestasi panas bumi permukaan berupa kolam mata air panas. Lokasi penelitian dapat dilihat pada Gambar 1 di bawah ini:

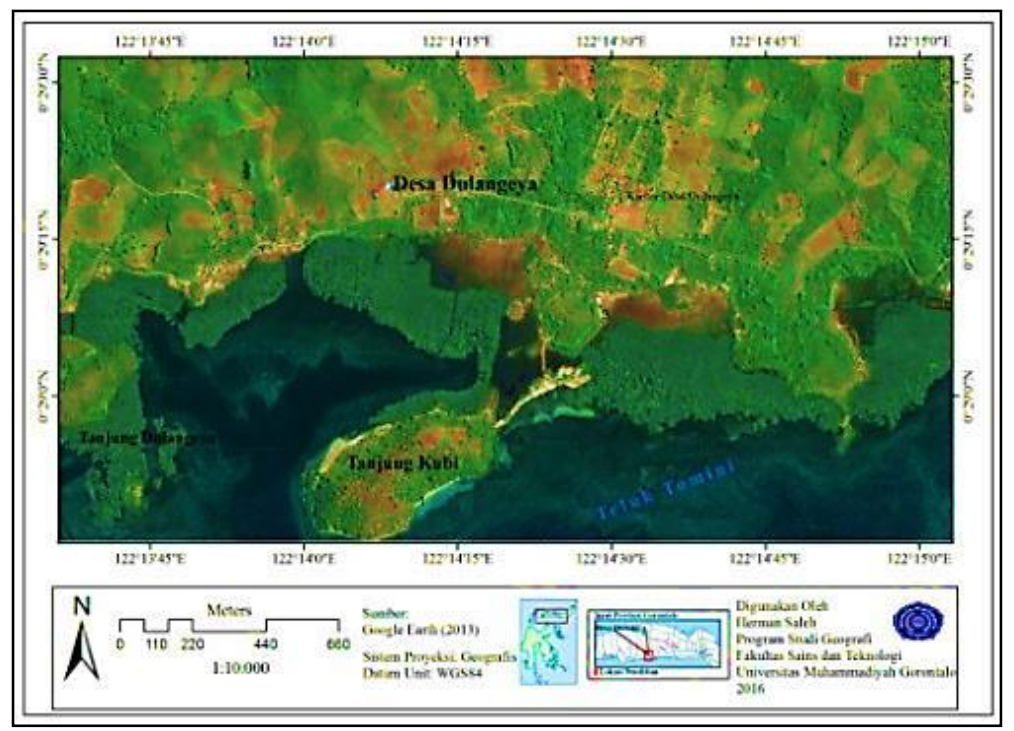

Gambar 1. Lokasi Penelitian Di Desa Dulangeya ( Sumber: GoogleEarth, 2017) 
Penelitian ini menggunakan peta lereng, peta tutupan lahan dan peta geologi yang akan saling di-overlay, sehingga menghasilkan peta kondisi bentang alam Desa Dulangeya. Peta bentang alam dalam penelitian ini digunakan untuk mengetahui kondisi gemorfologi Desa Dulangeya yang terdiri dari 5 titik sampel. Peta lereng, peta tutupan lahan dan peta geologi dalam penelitian ini merupakan data yang dipeoleh dari BPS KEMENTAN 2010. Sedangkan, perolehan data potensi alam seperti pesisir laut berpasir putih, kawasan mangrove, dan sumber mata air panas di lokasi penelitian akan dilakukan dengan survei lapangan. Survei lapangan dilakukan dengan cara pengambilan titik koordinat menggunakan GPS Oregon 650 dan disertai dengan dokumentasi lapangan. Hasil dari survey lapangan akan dianalisis secara spasial sehingga dapat menghasilkan peta potensi wisata alam Desa Dulangeya.

Selain itu, adapun sebagai pendukung dalam penelitian ini maka perolehan data potensi alam juga akan menggunakan metode wawancara yang terdiri atas populasi dan sampel. Populasi dalam wawancara didasarkan kepada tanggapan masyarakat dan aparat pemerintah Desa Dulangeya Kecamatan Botumoito, sedangkan sampel adalah bagian dari populasi yang diambil sebagai sumber data dan dapat mewakili seluruh populasi. Pengambilan sampel dilakukan menggunakan kuisioner dengan tehnik purposive sampling atau disebut sebagai sampel bertujuan. Penyebaran kuisioner dibagikan kepada 30 responden meliputi 10 responden staf aparatur Desa Dulangeya, 10 responden tokoh masyarakat dan 10 responden pengurus Karang Taruna. Pengambilan sampel dalam penelitian hanya mengacu kepada masyarakat yang tergolong dalam kepemerintahan Desa Dulangeya sebab ketersedian potensi alam di Desa Dulangeya yang layak untuk dijadikan sebagai obyek daya tarik wisata secara umum hanya diketahui oleh masyarakat yang tergolong dalam kepemerintahan Desa Dulangeya. Hasil wawancara dalam penilitian ini sebagai data pendukung untuk analisis skoring. Kerangka alir penelitian dapat dilihat pada Gambar 2 di bawah ini:

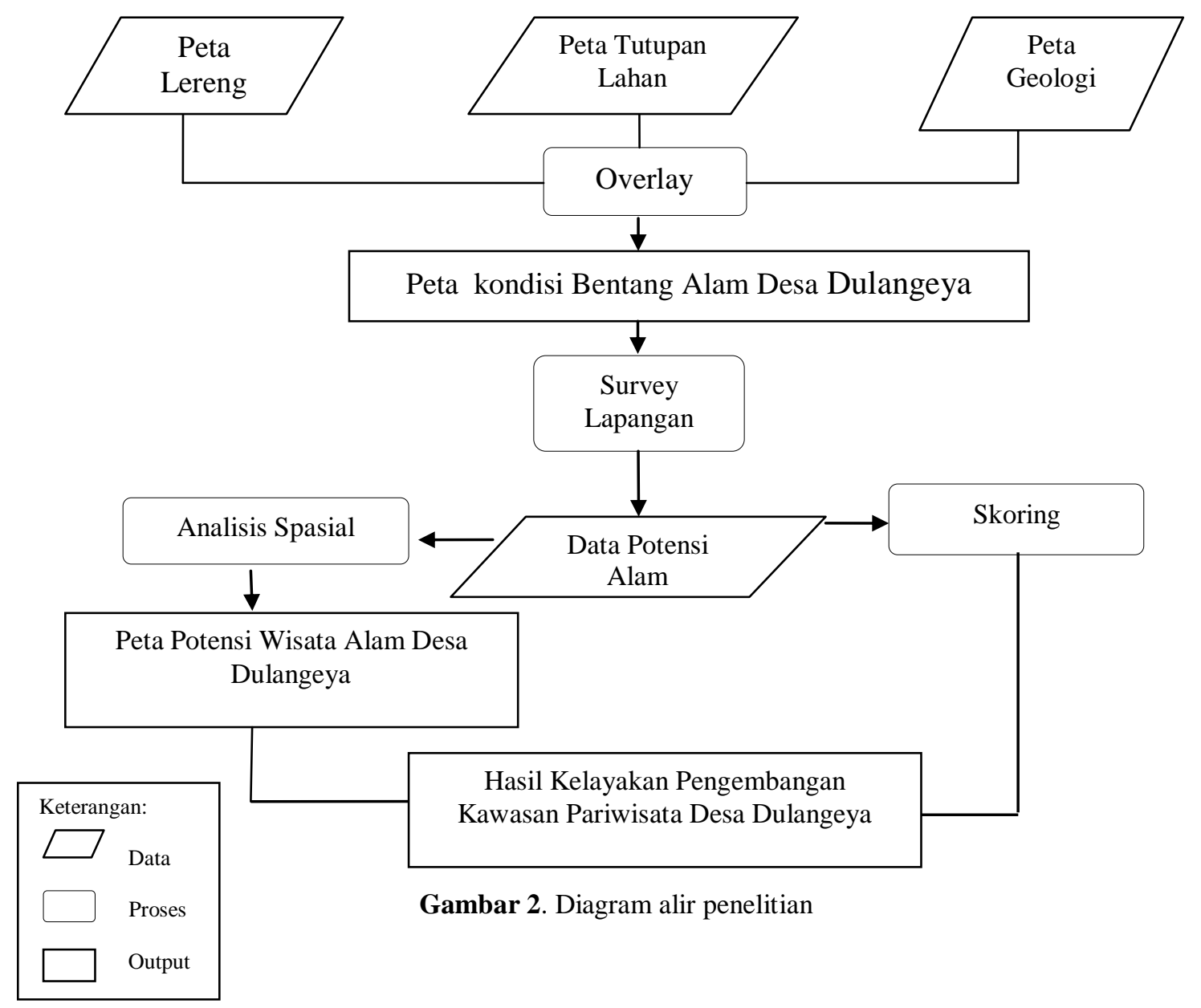


Analisis skoring dalam penelitian ini mengunakan Pedoman Analisis Daerah Operasi Obyek dan Daya Tarik Wisata Alam Dirjen PHKA, 2003 (dalam Maharani, 2016). Sesuai dengan nilai yang telah ditentukan untuk masing-masing kriteria. Jumlah nilai untuk satu kriteria dapat dihitung menggunakan rumus di bawah ini.

Keterangan :

$$
\mathrm{S}=\mathrm{N} \times \mathrm{B}
$$

$\mathrm{S}=$ Skor/nilai suatu kriteria

$\mathrm{N}=$ jumlah nilai unsur

$\mathrm{B}=$ bobot nilai

Kriteria daya tarik diberi 6 karena daya tarik merupakan faktor utama alasan seseorang melakukan perjalanan wisata. Aksesibilitas diberi bobot 5 karena merupakan faktor penting yang mendukung wisatawan dapat melakukan kegiatan wisata. Untuk akomodasi serta sarana dan prasarana diberi bobot 3 karena hanya bersifat sebagai penunjang dalam kegiatan wisata. Hasil pengolahan data tersebut kemudian diuraikan secara deskriptif. Kriteria penilaian obyek dan daya tarik wisata alam berdasarkan (Pedoman Analisis Daerah Operasi dan Daya Tarik Wisata, Direktorat Jenderal Perlindungan Hutan dan Konservasi Alam, 2003 dalam Maharani, 2016).

Tabel 1. Kriteria Penilaian Daya Tarik (Bobot 6 )

\begin{tabular}{|c|c|c|c|c|c|c|}
\hline \multirow{3}{*}{$\begin{array}{c}\text { No } \\
1\end{array}$} & \multirow{3}{*}{$\begin{array}{l}\text { Unsur/ Sub Unsur } \\
\text { Keunikan sumber daya alam } \\
\text { a. Air Terjun } \\
\text { b. Flora } \\
\text { c. Fauna } \\
\text { d. Adat Istiadat/ Kebudayaan } \\
\text { e. Sungai }\end{array}$} & \multicolumn{5}{|c|}{ Nilai } \\
\hline & & $\begin{array}{c}\text { Ada } \\
5\end{array}$ & $\begin{array}{c}\text { Ada } \\
4\end{array}$ & $\begin{array}{c}\text { Ada } \\
3\end{array}$ & $\begin{array}{c}\text { Ada } \\
2\end{array}$ & $\begin{array}{c}\text { Ada } \\
1\end{array}$ \\
\hline & & 30 & 25 & 20 & 15 & 10 \\
\hline 2 & $\begin{array}{l}\text { Banyaknya sumberdaya alam yang menonjol } \\
\text { a. Batuan }\end{array}$ & $\begin{array}{c}\text { Ada } \\
5\end{array}$ & $\begin{array}{c}\text { Ada } \\
4\end{array}$ & $\begin{array}{c}\text { Ada } \\
3\end{array}$ & $\begin{array}{c}\text { Ada } \\
2\end{array}$ & $\begin{array}{c}\text { Ada } \\
1\end{array}$ \\
\hline & $\begin{array}{l}\text { b. Flora } \\
\text { c. Fauna } \\
\text { d. Air } \\
\text { e. Gejala Alam }\end{array}$ & 30 & 25 & 20 & 15 & 10 \\
\hline 3 & $\begin{array}{l}\text { Kegiatan wisata alam yang dapat dilakukan: } \\
\text { a. Menikmati Keindahan alam }\end{array}$ & $\geq 5$ & $\begin{array}{c}\text { Ada } \\
4\end{array}$ & $\begin{array}{c}\text { Ada } \\
3\end{array}$ & $\begin{array}{c}\text { Ada } \\
2\end{array}$ & $\begin{array}{c}\text { Ada } \\
1\end{array}$ \\
\hline & $\begin{array}{l}\text { b. Melihat Flora dan Fauna } \\
\text { c. Trekking } \\
\text { d. Penelitian/ Pendidikan } \\
\text { e. Berkemah } \\
\text { f. Kegiatan Olahraga }\end{array}$ & 30 & 25 & 20 & 15 & 10 \\
\hline 4. & $\begin{array}{l}\text { Kebersihan lokasi obyek wisata, tidak ada } \\
\text { pengaruh dari: }\end{array}$ & Ada & Ada & Ada & Ada & $\begin{array}{l}\text { Tdk } \\
\text { Ada }\end{array}$ \\
\hline & $\begin{array}{l}\text { a. Industri } \\
\text { b. Jalan Ramai } \\
\text { c. Pemukiman Penduduk } \\
\text { d. Sampah } \\
\text { e. Vandalisme (coret-coret) } \\
\text { f. Pencemar lainnya }\end{array}$ & $\frac{6}{30}$ & $\frac{5}{25}$ & $\frac{3-4}{20}$ & $\frac{1-2}{15}$ & 10 \\
\hline 5. & $\begin{array}{l}\text { Keamanan kawasan: } \\
\text { a. Tidak ada arus berbahaya }\end{array}$ & $\geq 5$ & $\begin{array}{c}\text { Ada } \\
4 \\
\end{array}$ & $\begin{array}{c}\text { Ada } \\
3 \\
\end{array}$ & $\begin{array}{c}\text { Ada } \\
2\end{array}$ & $\begin{array}{c}\text { Ada } \\
1 \\
\end{array}$ \\
\hline & $\begin{array}{l}\text { b. Tidak ada perambahan dan penerbangan } \\
\text { liar } \\
\text { c. Tidak ada pencurian } \\
\text { d. Tidak ada penyakit berbahaya seperti } \\
\text { malaria }\end{array}$ & 30 & 25 & 20 & 15 & 10 \\
\hline
\end{tabular}


e. Tidak ada kepercayaan yang mengganggu

f. Tidak ada tanah longsong

6. Kenyamanan:

a. Udara yang bersih dan sejuk

b. Bebas dari bau yang mengganggu

\begin{tabular}{ccccc}
$\geq 5$ & Ada & Ada & Ada & Ada \\
& 4 & 3 & 2 & 1 \\
\hline 30 & 25 & 20 & 15 & 10
\end{tabular}

c. Bebas dari kebisingan

d. Tidak ada lalu lintas yang mengganggu

e. Pelayanan terhadap pengunjung yang baik

f. Tersedianya sarana dan prasarana

Ket: * Skor total maksimum penilaian daya tarik $=$ bobot daya tarik $\mathrm{x}$ nilai unsur $=1080$. (Sumber: Pedoman Analisis Daerah Operasi dan Daya Tarik Wisata, Direktorat Jenderal Perlindungan Hutan dan Konservasi Alam, 2003 dalam Maharani, 2016).

Tabel 2. Kriteria Penilaian Aksesibilitas (Bobot 5)

\begin{tabular}{|c|c|c|c|c|c|}
\hline No & Unsur/ Sub Unsur & & & Nilai & \\
\hline \multirow[t]{2}{*}{1.} & Kondisi Jalan & Baik & Cukup & Sedang & Buruk \\
\hline & & 30 & 25 & 20 & 15 \\
\hline \multirow[t]{2}{*}{2.} & Jarak & $<5 \mathrm{~km}$ & $5-10$ & $10-15 \mathrm{~km}$ & $>15 \mathrm{~km}$ \\
\hline & & 30 & 25 & 20 & 10 \\
\hline \multirow[t]{2}{*}{3.} & Tipe Jalan & $\begin{array}{c}\text { Jalan } \\
\text { Aspal > } \\
3 \mathrm{~m}\end{array}$ & $\begin{array}{l}\text { Jalan aspal } \\
\text { lebar }<3 \mathrm{~m}\end{array}$ & Jalan batu/ makadam & Jalan tanah \\
\hline & & 30 & 25 & 20 & 15 \\
\hline \multirow[t]{2}{*}{4.} & $\begin{array}{l}\text { Waktu tempuh dari } \\
\text { pusat kota }\end{array}$ & $1-3 \mathrm{jam}$ & 2-3 jam & 3-4 jam & $\geq 5$ jam \\
\hline & & 30 & 25 & 20 & 15 \\
\hline
\end{tabular}

Ket: *Skor total maksimum penilaian aksesibilas $=$ bobot aksesibilitas $\mathrm{x}$ nilai unsur aksesibilitas $=600$. (Sumber: Pedoman Analisis Daerah Operasi dan Daya Tarik Wisata, Direktorat Jenderal Perlindungan Hutan dan Konservasi Alam, 2003 dalam Maharani, 2016).

Tabel 3. Kriteria Penilaian Akomodasi (Bobot 3)

\begin{tabular}{|c|c|c|c|c|c|c|}
\hline No & Unsur/ Sub Unsur & & & Nila & & \\
\hline \multirow{2}{*}{1.} & \multirow{2}{*}{ Jumlah Akomodasi } & $\geq 4$ & Ada 3 & Ada 2 & Ada 1 & Tidak Ada \\
\hline & & 30 & 25 & 20 & 15 & 10 \\
\hline \multirow{2}{*}{\multicolumn{2}{|c|}{ 2. Jumlah Kamar }} & $>100$ & $75-100$ & $30-75$ & $<30$ & Tidak Ada \\
\hline & & 30 & 25 & 20 & 15 & 10 \\
\hline
\end{tabular}

Ket: *Skor total maksimum penelitian akomodasi $=$ bobot akomodasi $\mathrm{x}$ nilai unsur akomodasi $=180$. (Sumber: Pedoman Analisis Daerah Operasi dan Daya Tarik Wisata, Direktorat Jenderal Perlindungan Hutan dan Konservasi Alam, 2003 dalam Maharani, 2016).

Tabel 4. Kriteria Penilaian Sarana dan Prasarana Penunjang (Bobot 3)

\begin{tabular}{|c|c|c|c|c|c|c|}
\hline \multirow[b]{2}{*}{ No } & \multirow[b]{2}{*}{ Unsur/ Sub Unsur } & \multicolumn{5}{|c|}{ Jumlah } \\
\hline & & $\geq 4$ & Ada & Ada 2 & Ada 1 & $\begin{array}{c}\text { Tidak } \\
\text { Ada }\end{array}$ \\
\hline 1. & $\begin{array}{l}\text { Prasarana: Kantor pos, jaringan } \\
\text { telepon, puskesmas, jaringan listrik, } \\
\text { jaringan air minum }\end{array}$ & 50 & 40 & 30 & 20 & 10 \\
\hline 2. & $\begin{array}{l}\text { Sarana penunjang: rumah makan, } \\
\text { pusat pembelanjaan/ pasar, bank, } \\
\text { toko cinderamata, transportasi }\end{array}$ & 50 & 40 & 30 & 20 & 10 \\
\hline
\end{tabular}


Ket: * Skor total maksimum penilaian sarana dan prasarana penunjang = bobot sarana dan prasarana $\mathrm{x}$ nilai unsur sarana dan prasarana $=300$. (Sumber: Pedoman Analisis Daerah Operasi dan Daya Tarik Wisata, Direktorat Jenderal Perlindungan Hutan dan Konservasi Alam, 2003 dalam Maharani, 2016).

Skor yang diperoleh kemudian dibandingkan dengan skor total suatu kriteria apabila setiap sub kriteria memiliki nilai maksimum yaitu 5. Hasil penilaian tersebut adalah sebagai berikut:

Nilai indeks kelayakan suatu obyek wisata

$$
\frac{\mathrm{A}}{\mathrm{B}} \times 100 \%
$$

Keterangan :

A: Skor kriteria

B: Skor Total kriteria

Karsudi, et al (2010) menyatakan setelah dilakukan perbandingan, maka akan diperoleh indeks kelayakan dalam persen. Indeks kelayakan suatu kawasan ekowisata adalah sebagai berikut:
a) Tingkat kelayakan $>66,6 \%$
: layak dikembangkan
b) Tingkat kelayakan $33,3 \%-66,6 \%$
: belum layak dikembangkan
c) Tingkat kelayakan $<33,3 \%$
: tidak layak dikembangkan

\section{HASIL DAN PEMBAHASAN}

\section{Kondisi Geomorfologi Desa Dulangeya}

Kondisi geomorfologi dalam penelitian ini diperoleh dari peta kondisi bentang alam Desa Dulangeya yang merupakan hasil overlay peta tutupan lahan, peta geologi dan peta lereng, berdasarkan peta tersebut bahwa kondisi geomorfologi Desa Dulangeya yang terdiri dari 5 titik sampel yaitu tutupan lahan (hutan mangrove primer, hutan mangrove sekunder, pertanian lahan kering, pertanian lahan kering bercampur semak/belukar), tatanan geologi aluvium dan granodiorit serta kemiringan lereng yang berkisar antara 2-5\% dan 5-15\%.

\section{a. Kondisi Tutupan Lahan Desa Dulangeya}

Peta tutupan lahan Desa Dulangeya disajikan pada Gambar 3. Berdasarkan peta tersebut dijelaskan bahwa tutupan lahan di area lokasi penelitian terdiri atas hutan mangrove primer, hutan mangrove sekunder, pertanian lahan kering, pertanian lahan kering bercampur semak/belukar.

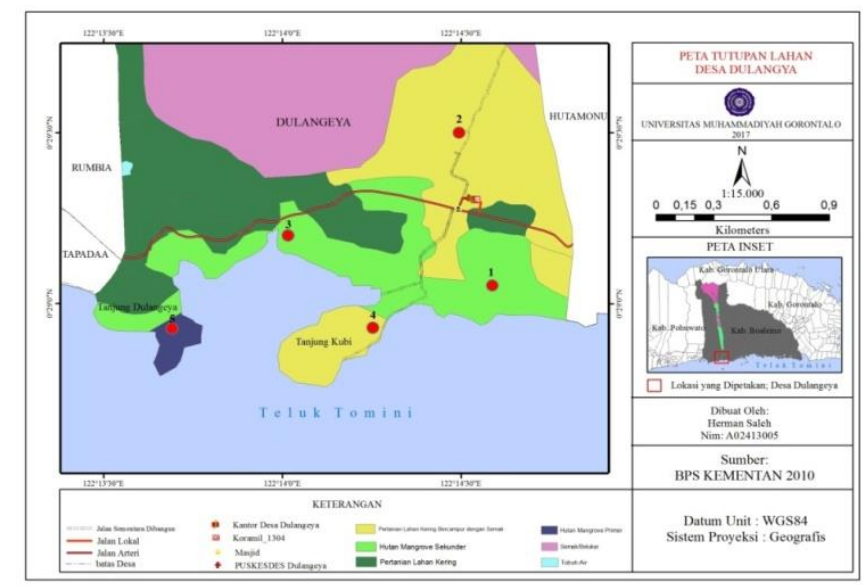

Gambar 3. Peta Tutupan Lahan Desa Dulangeya (Sumber: Hasil Olah Data, 2017)

b. Kondisi Geologi Desa Dulangeya

Peta geologi di Desa Dulangeya disajikan pada Gambar 4. Berdasarkan peta tersebut dijelaskan bahwa klasifikasi geologi di Desa Dulangeya khususnya di area lokasi penelitian terdiri atas aluvium dan granodiorit. Formasi geologi pada lokasi penelitian yaitu terdiri dari 
batuan Aluvium dan Granodiorit. Batuan aluvium adalah batuan seperti halnya pasir, lanau, lumpur kerikil dan kerakal sedangkan batuan Granodiorit adalah batuan beku seperti halnya granit, dasit dan monzonit kuarsa (Bachri, 1993).

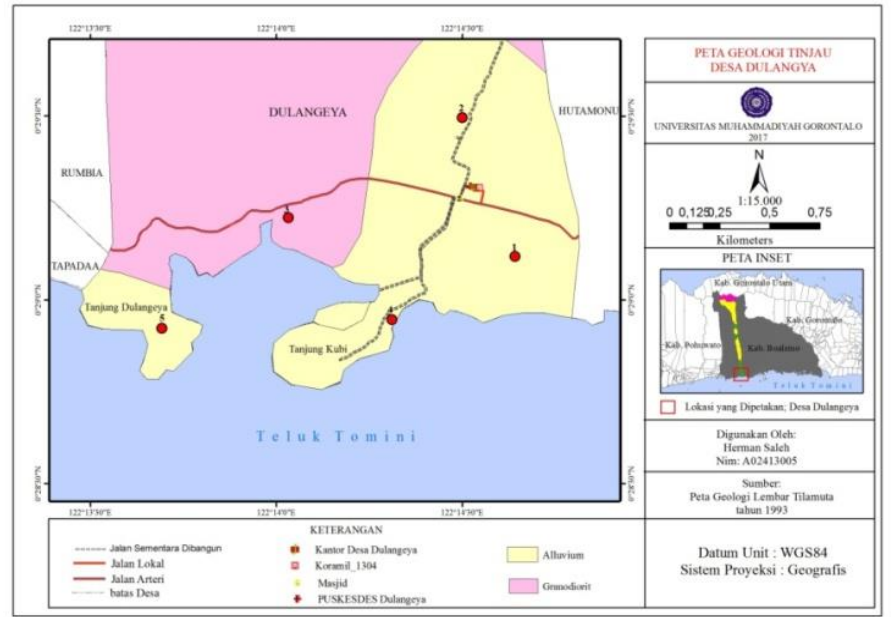

Gambar 4. Peta Geologi Tinjau Desa Dulangeya (Sumber: Hasil Olah Data Sekunder, 2017)

c. Kondisi Kemiringan Lereng Desa Dulangeya

Peta lereng Desa Dulangeya disajikan pada Gambar 5. Berdasarkan peta tersebut dijelaskan bahwa kemiringan lereng di Desa Dulangeya khususnya di area lokasi penelitian berkisar antara 2-5\% dan 5-15\%. Hasil dari peta kemiringan lereng bahwa di lokasi area penelitian memiliki kemiringan lereng yang terdiri dari spot $1(5-15 \%)$, spot $2(5-15 \%)$, spot 3 $(2-5 \%)$, spot $4(5-15 \%)$, spot $5(2-5 \%)$.

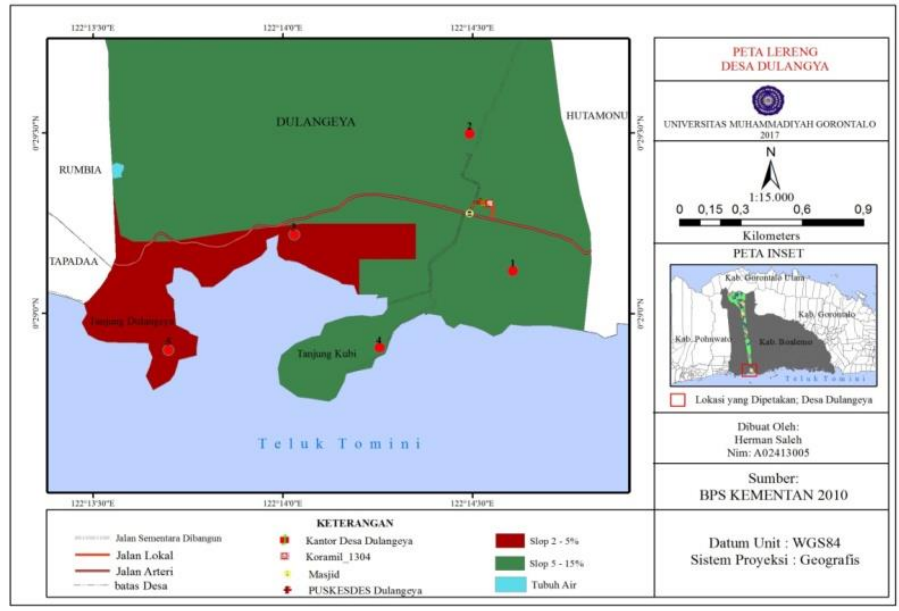

Gambar 5. Peta Lereng Desa Dulangeya (Sumber: Hasil Olah Data, 2017)

Data Sekunder seperti peta tutupan lahan, peta geologi dan peta lereng yang di overlay sehingga menghasilkan peta kondisi bentang alam Desa Dulangeya dalam hal ini digunakan untuk mengetahui kondisi geomorfologi Desa Dulangeya disajikan pada Gambar 6. Dengan demikian dari Gambar 6 dapat diketahui bahwa letak ataupun jarak dari setiap potensi wisata yang ada di Desa Dulangeya it sendiri. Demikian pula pada Gambar 6 dapat diketahui kondisi jalan menuju titik potensi wisata yang terssdia di Desa Dulangeya, pada Gambar 6 pula sudah disajakan foto untuk setiap potensi yang tersedia disetiap titik yang menjadi potensi wisata sahingganya peta tersebut dapat mempermudah setiap pengujung untuk mengetahui lokasi ataupun daya tarik wisata disetiap titik. 


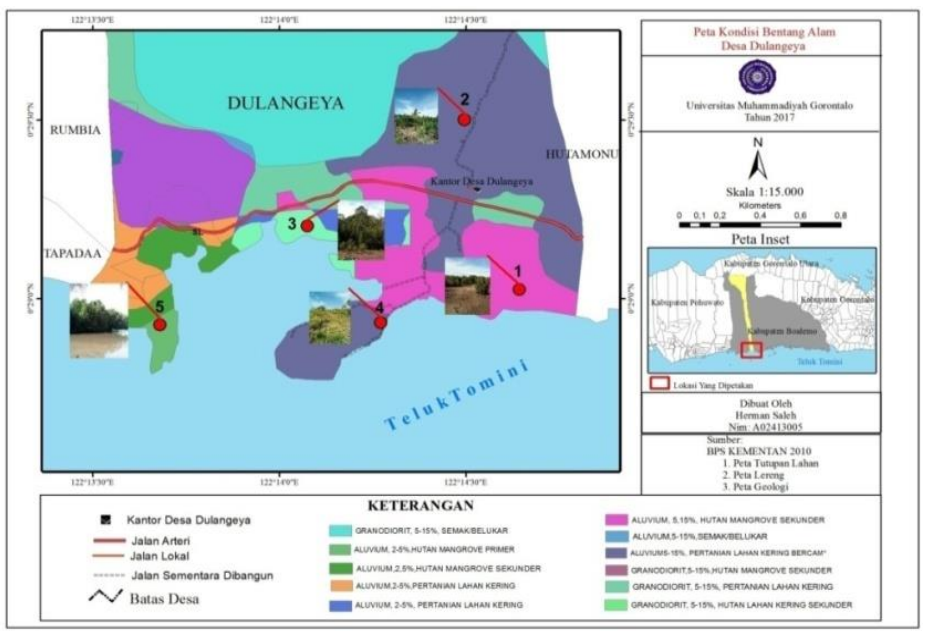

Gambar 6. Peta Kondisi Bentang Alam Desa Dulangeya (Sumber: Hasil Olah Data, 2017)

\section{Analisis Spasial Potensi Alam Desa Dulangeya}

Berdasarkan hasil survey lapangan dan hasil olahan data sekunder pada Gambar 6 bahwa di Desa Dulangeya terdapat beberapa potensi alam yang dapat dijadikan sebagai obyek wisata alam yaitu sumber mata air panas, mangrove, dan pesisir pantai berpasir putih. Akan tetapi potensi alam yang tersedia tidak dikembangkan menjadi salah satu obyek wisata. Dalam penelitian ini keberadaan potensi alam di Desa Dulangeya akan di anaslisis secara spasial menggunakan data sekunder seperti peta tutupan lahan, peta geologi dan peta lereng sehingga dari hasil analisis tersebut dapat diperoleh informasi terkait dengan tutupan lahan, tataran geologi serta kemiringan lereng.

Kondisi potensi alam di Desa Dulangeya disajikan pada Gambar 7. Berdasarkan peta tersebut dapat diketahui bahwa tutupan lahan, kemiringan lereng serta tatanan geologi pada lokasi potensi sumber mata air panas yaitu tutupan lahan pertanian lahan kering bercampur semak/belukar, ketinggian lereng yang berkisar 5-15\% serta memiliki tataran geologi berupa aluvium. Demikian pula berdasarkan peta tersebut dapat diketahui bahwa tataran geologi, tutupan lahan serta kemiringan lereng pada lokasi mangrove yaitu memiliki tataran geologi aluvium, kemiringan lereng berkisar 5-15\% serta memiliki tutupan lahan hutan mangrove sekunder. Selain itu, berdasarkan peta tersebut dapat diperoleh pula informasi terkait tatanan geologi, tutupan lahan dan kemiringan lereng di lokasi potensi pesisir berpasir putih yaitu memiliki tataran geologi aluvium, kemiringan lereng berikisar 2-5\% serta memiliki tutupun lahan semak/belukar. Dengan demikian berdasarkan hasil uraian kondisi potensi alam Desa Dulangeya maka potensi alam yang tesedia di Desa Dulangeya dapat dijadikan sebagai salah satu destinasi wisata dengan nuansa alam yang beragam.

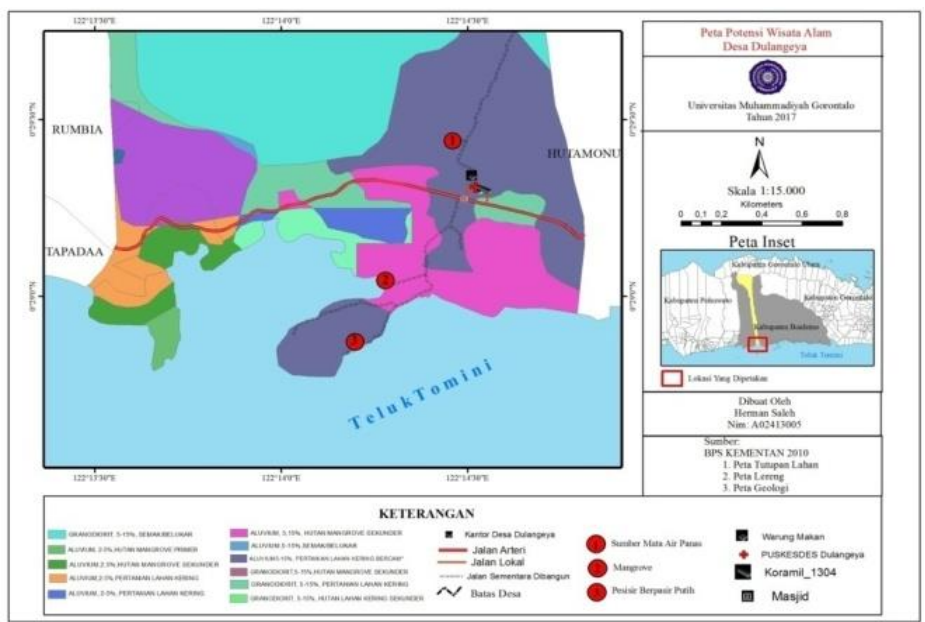

Gambar 7. Peta Potensi Wisata Alam Desa Dulangeya (Sumber: Hasil Olah Data, 2017) 


\section{Analisis Skoring}

Tabel 5 di bawah ini menjelaskan hasil kriteria penilaian daya tarik di Desa Dulangeya, berdasarkan tabel tersebut bahwa Desa Dulangeya memiliki keunikan sumber daya alam (flora, sumber mata mata air panas, sungai, fauna, adat istiadat), memiliki kebersihan lokasi (Tidak adanya industri, pemukiman pnduduk, sampah-sampah, vandalisme (coret-coret) dan pencemar lainnya), memiliki kegiatan wisata (Menikmati keindahan alam, melihat flora dan fauna, trekking, penelitian dan berkemah), memiliki keamanan kawasan (tidak ada arus sungai yang berbahaya, Tidak ada perambahan dan penebangan liar, tidak ada pencurian, tidak ada penyakit berbahaya seperti malaria, tidak ada kepercayaan yang mengganggu, dan tidak ada tanah longsor), serta memiliki sumber daya alam yang menonjol (Flora yang terdapat pada lokasi ini adalah mangrove, Fauna yang terdapat di lokasi ini adalah berbagai jenis spesies yang hidup di mangrove (siput bakau). Sumber alam yang menonjol lain yaitu batuan, air dan gejala alam). Berdasarkan urain tersebut bahwa Desa Dulangeya memiliki daya tarik wisata yang beragam dan dapat memanjakan mata bagi para pengunjung lokal maupun mancanegara.

Tabel 5. Hasil Kriteria Penilaian Daya Tarik (Bobot 6 )

\begin{tabular}{|c|c|c|c|c|}
\hline Unsur/Sub unsur & Uraian & Bobot & Nilai & Skor Total/ST \\
\hline $\begin{array}{l}\text { Keunikan Sumber } \\
\text { Daya Alam }\end{array}$ & $\begin{array}{l}\text { Flora yang terdapat pada lokasi ini } \\
\text { yaitu mangrove dan juga keberadaan } \\
\text { sumber mata mata air panas, sungai, } \\
\text { fauna, adatistiadat. }\end{array}$ & 6 & 25 & 150 \\
\hline $\begin{array}{l}\text { Banyaknya Sumber } \\
\text { Daya Alam yang } \\
\text { menonjol }\end{array}$ & $\begin{array}{l}\text { Flora yang terdapat pada lokasi ini } \\
\text { adalah mangrove, Fauna yang } \\
\text { terdapat di lokasi ini adalah berbagai } \\
\text { jenis spesies yang hidup di } \\
\text { mangrove(siput bakau). Sumber alam } \\
\text { yang menonjol lain yaitu batuan, air } \\
\text { dan gejala alam. }\end{array}$ & 6 & 30 & 180 \\
\hline $\begin{array}{l}\text { Kegiatan wisata alam } \\
\text { yang dapat dinikmati }\end{array}$ & $\begin{array}{l}\text { Menikmati keindahan alam, melihat } \\
\text { flora dan fauna, trekking, penelitian } \\
\text { dan berkemah }\end{array}$ & 6 & 30 & 180 \\
\hline Kebersihan Lokasi & $\begin{array}{l}\text { Tidak adanya industri, pemukiman } \\
\text { pnduduk, sampah-sampah, } \\
\text { vandalisme (coret-coret) dan } \\
\text { pencemar lainnya. }\end{array}$ & 6 & 30 & 180 \\
\hline Keamanan kawasan & $\begin{array}{l}\text { Tidak ada arus sungai yang } \\
\text { berbahaya, Tidak ada perambahan } \\
\text { dan penebangan liar, tidak ada } \\
\text { pencurian, tidak ada penyakit } \\
\text { berbahaya seperti malaria, tidak ada } \\
\text { kepercayaan yang mengganggu, dan } \\
\text { tidak ada tanah longsor }\end{array}$ & 6 & 30 & 180 \\
\hline Kenyamanan & $\begin{array}{l}\text { Udara yang bersih dan sejuk, bebas } \\
\text { dari bau yang mengganggu, bebas } \\
\text { dari kebisingan, tidak ada lalu lintas } \\
\text { yang mengganggu, }\end{array}$ & 6 & 5 & 150 \\
\hline $\begin{array}{l}\text { Skor total potensi } \\
\text { daya tarik }\end{array}$ & & & 170 & 1020 \\
\hline
\end{tabular}

*(ST) adalah hasil kali antara bobot dan nilai. (Sumber: Hasil Olah Data, 2017)

Berdasarkan Tabel 5 di atas dapat dilihat bahwa keunikan sumberdaya alam dan kenyaman, memiliki skor total terendah yaitu 150. sedangkan untuk unsur/sub seperti kegiatan wisata alam yang dinikmati, kebersihan lokasi wisata, keamanan kawasan dan banyaknya sumber daya alam yang menonjol memiliki skor total tertinggi yaitu 180 . 
Tabel 6. Hasil Penilaian terhadap Komponen Aksesibilitas

\begin{tabular}{llccc}
\hline Unsur/Sub Unsur & Uraian & Bobot & Nilai & Skor Total (ST) \\
\hline Kondisi Jalan & Cukup & 5 & 25 & 125 \\
Jarak dari kota & $>15$ & 5 & 10 & 50 \\
Tipe jalan & Jalan batu & 5 & 20 & 100 \\
Waktu tempuh dari kota & $1-3$ jam & 5 & 30 & 150 \\
\hline Skor total aksesibilitas & & & 85 & 425 \\
\hline
\end{tabular}

*(ST) adalah hasil kali antara bobot dan nilai. (Sumber: Hasil Olah Data, 2017)

Berdasarkan Tabel 6 di atas dapat dilihat bahwa hasil Penilaian terhadap komponen aksesibilitas potensi yang akan menjadi obyek daya tarik wisata sudah tergolong cukup baik, meskipun jalannya masih jalan tanah akan tetapi sudah bisa dijangkau dengan kendaraan roda empat maupun roda tiga. Berdasarkan hasil wawancara bahwa waktu tempuh dari pusat kota Boalemo yaitu \pm satu jam.

Tabel 7. Hasil Penilaian Terhadap Komponen Akomodasi

\begin{tabular}{ccccc}
\hline No & Unsur/Sub Unsur & Bobot & Nilai & Skor Total (ST) \\
\hline 1 & Jumlah Akomodasi & 3 & 10 & 30 \\
2 & Jumlah Kamar & 3 & 10 & 30 \\
\hline & & & 20 & 60 \\
\hline
\end{tabular}

*(ST) adalah hasil kali antara bobot dan nilai. (Sumber: Olah Data, 2017)

Berdasarkan tabel 7 bahwa keberadaan akomodasi di Desa Dulangeya memang belum ada akan tetapi potensi alam yang tersedia jika dikembangkan menjadi salah satu obyek wisata maka akan diadakan fasilitas akomodasi tersebut.

Tabel 8. Hasil Kriteria Penilaian terhadap Komponen Sarana dan Prasarana Penunjang

\begin{tabular}{ccccc}
\hline Unsur/Sub Unsur & Bobot & Nilai & Skor Total (ST) \\
\hline Prasarana penunjang & - jaringan listrik & 3 & 40 & 120 \\
$-\quad$ Jaringan telepon & $\begin{array}{l}\text { - jaringan air minum } \\
-\quad \text { Puskesmas }\end{array}$ & 3 & 30 & 90 \\
$\begin{array}{l}\text { Sarana penunjang } \\
-\quad \text { Transportasi }\end{array}$ & - Warung makan & 70 & 210 \\
\hline Skor total sarana dan prasarana & & & \\
\hline
\end{tabular}

*(ST) adalah hasil kali antara bobot dan nilai. (Sumber: Olah Data, 2017)

Prasarana penunjang yang ada di Desa Dulangeya adalah klinik, tempat ibadah, jaringan listrik, jaringan telepon dan jaringan air minum. Sedangkan untuk sarana yang terdapat di Desa Dulangeya masih minim karena hanya terdapat transportasi yang melintasi kawasan obyek wisata ini yaitu sepeda motor, bus, mobil pribadi, dan truk. Dengan demikian hasil akhir dari penilian potensi daya tarik wisata di Desa Dulangeya dapat dilihat pada tabel 9.

Tabel 9. Hasil Penilaian Potensi Daya Tarik Wisata di Desa Dulangeya

\begin{tabular}{|c|c|c|c|c|c|c|c|c|}
\hline No & Kriteria & & Bobot & Nilai* & Skor ${ }^{* *}$ & $\begin{array}{l}\text { Skor } \\
\max ^{* * * * *}\end{array}$ & Indeks $(\%)^{* * * * *}$ & Keterangan \\
\hline 1 & Daya tarik & & 6 & 170 & 1020 & 1080 & 94.44 & Layak \\
\hline 2 & Aksesibilitas & & 5 & 85 & 425 & 600 & 70,83 & Layak \\
\hline 3 & akomodasi & & 3 & 20 & 60 & 180 & 33,33 & Belum layak \\
\hline 4 & $\begin{array}{l}\text { Sarana } \\
\text { prasarana }\end{array}$ & dan & 3 & 70 & 210 & 300 & 70 & Layak \\
\hline
\end{tabular}

(Sumber: Olah Data, 2017)

Ket :

*Hasil penilaian terhadap obyek dan daya tarik wisata

**Perkalian antara bobot dengan nilai

***Skor tertinggi untuk setiap kriteria

****Indeks kelayakan: perbandingan skor dengan skor tertinggi dalam \% 


\section{KESIMPULAN}

Berdasarkan hasil analisis spasial dan hasil skoring yang didukung oleh obsrvasi lapangan dan wawancara bahwa potensi sumber daya alam di Desa Dulangeya layak untuk dijadikan sebagai kawasan wisata. Dari hasil observasi lapangan dapat disimpulkan bahwa potensi sumber daya alam yang layak untuk dijadikan sebagai obyek daya tarik wisata yaitu sumber mata air panas, mangrove, dan pesisir pantai berpasir putih. Berdasarkan anilisis spasial dan analisis skoring bahwa potensi alam yang tersedia di Desa Dulangeya layak untuk dijadikan sebagai kawasan strategis pariwisata, dari hasil skoring diperoleh nilai untuk potensi daya tarik di Desa Dulangeya yaitu 94,44 sehingga dari nilai tersebut dapat disimpulkan bahwa hasil identifikasi potensi alam di Desa Dulangeya layak untuk dikembangan menjadi kawasan wisata.

\section{UCAPAN TERIMAKASIH}

Penulis mengucapkan terima kasih kepada pemerintah Desa Dulangeya yang telah mengijinkan saya untuk melakukan penelitian terkait dengan Potensi Pengembangan Kawasan Pariwisata Alam Desa Dulangeya.

\section{DAFTAR PUSTAKA}

Amirudin., F.A. 2011. Kajian Potensi Wisata Pass Dalam Analisis Spasial. Skiripsi. Fakultas Keguruan dan Ilmu Pendidikan. Universitas Sebelas Maret. Surakarta.

Bachri, S., Sukindo., Ratman, N. 1993. Peta Geologi Lembar Tilamuta, Sulawesi. Pusat Penelitian dan Pengembangan Geologi.

Bafdal, N., Amaru, K., Boy M.P.P. 2011. Sistem Informasi Geografi. Bandung, Jur. TMIP. FTIP. Unpad.

Kantor Kepala Desa (2016), Profil Desa Dulangeya. Kecamatan Botumoito, Kabupaten Boalemo.

Karsudi, Soekmadi, R., Kartodihardjo, H. 2010. Strategi Pengembangan Ekowisata di Kabupaten Kepulauan Yapen Provinsi Papua. JMHT. Vol. XVI, no. 3. Hal 150.

Maharani. I. 2016. Analisis Kelayakan Potensi Ekowisata Pada Kawasan Wisata Alam Bungi Kokalukuna Kota Baubau. Skripsi. Program Studi Manajmen Hutan. Jurusan Kehutanan. Fakultas Kehutanan dan Ilmu Lingkungan. Universitas Halu Oleo.

Republik Indonesia, 1990. Undang-Undang Kepariwisataan No. 9 Tahun 1990. Jakarta: Sekretariat Negara.

Republik Indonesia, 2007. Undang-Undang Pengelolaan Wilayah pesisir dan Pulau-Pulau Kecil. Nomor 27 Tahun 2007. Jakarta: Sekretariat Negara.

Republik Indonesia, 2009. Undang-Undang Kepariwisataan No. 10 Tahun 2009. Jakarta: Sekretariat Negara.

Soebagyo, 2012. Strategi Pengembangan Pariwisata di Indonesia. Jurnal Liquidity. Volume 1. No. 2. Hal 1.

Suhamdani, H.H. 2013. Analisis pengembangan pariwisata alam lewaja Di Kabupaten Enrekang. Skripsi. Jurusan Ilmu Politik dan Ilmu Pemerintahan, Fakultas Ilmu Sosial dan Ilmu Politik. Universitas HasanuddinMakassar

Taufik, M., Wandini A.I. 2012. Pengembangan Websig Obyek Wisata dan Budayadi Kabupaten Mojokerto. Jur.Teknik Geomatika. Hal 1.

Trianita., R. Penilaian Potensi Wisata Kawasan Muaro Silokek Durian Gadang Sebagai Alternatif Pemanfaatan Sumber Daya Berkelanjutan. Skripsi. Departemen Ekonomi Sumberdaya dan Lingkungan. Fakultas Ekonomi dan Manajemen. Institut Pertanian Bogor.

Tumimomor, M., Jando, E., Meolbatak, E. 2013. Sistem Informasi GeografisPariwisata Kota Kupang. Jurnal Nasional Pendidikan Teknik Informatika.Volume 1. No. 2. Hal 144.

Warpani P., Suwardjoko., Indira. 2007. Pariwisata Dalam Tata Ruang Wilayah. Penerbit ITB. 